\title{
Propulsion Technology Development for Sample Return Missions under NASA's ISPT Program
}

\author{
David J. Anderson ${ }^{1}$, Eric J. Pencil ${ }^{2}$, Daniel Vento ${ }^{3}$ \\ NASA Glenn Research Center, Cleveland, OH 44135 \\ John W. Dankanich ${ }^{4}$ \\ Gray Research, Inc., Cleveland, OH 44135 \\ Michelle M. Munk ${ }^{5}$, David Hahne ${ }^{6}$ \\ NASA Langley Research Center, Hampton, VA 23681
}

\begin{abstract}
The In-Space Propulsion Technology (ISPT) Program was tasked in 2009 to start development of propulsion technologies that would enable future sample return missions. Sample return missions could be quite varied, from collecting and bringing back samples of comets or asteroids, to soil, rocks, or atmosphere from planets or moons. The paper will describe the ISPT Program's propulsion technology development activities relevant to future sample return missions. The sample return propulsion technology development areas for ISPT are: 1) Sample Return Propulsion (SRP), 2) Planetary Ascent Vehicles (PAV), 3) Entry Vehicle Technologies (EVT), and 4) Systems/mission analysis and tools that focuses on sample return propulsion. The Sample Return Propulsion area is subdivided into: a) Electric propulsion for sample return and low cost Discovery-class missions, b) Propulsion systems for Earth Return Vehicles (ERV) including transfer stages to the destination, and c) Low TRL advanced propulsion technologies. The SRP effort will continue work on HIVHAC thruster development in FY2011 and then transitions into developing a HIVHAC system under future Electric Propulsion for sample return (ERV and transfer stages) and low-cost missions. Previous work on the lightweight propellant-tanks will continue under advanced propulsion technologies for sample return with direct applicability to a Mars Sample Return (MSR) mission and with general applicability to all future planetary spacecraft. A major effort under the EVT area is multi-mission technologies for Earth Entry Vehicles (MMEEV), which will leverage and build upon previous work related to Earth Entry Vehicles (EEV). The major effort under the PAV area is the Mars Ascent Vehicle (MAV). The MAV is a new development area to ISPT, and builds upon and leverages the past MAV analysis and technology developments from the Mars Technology Program (MTP) and previous MSR studies.
\end{abstract}

\footnotetext{
${ }^{1}$ Acting ISPT Program Manager, ISPT, 21000 Brookpark Road/MS 77-4, AIAA Member

${ }^{2}$ Propulsion Project Manager, ISPT, 21000 Brookpark Road/MS 77-4, AIAA Associate Fellow

${ }^{3}$ ISPT Integration Manager, ISPT, 21000 Brookpark Road/MS 77-4

${ }^{4}$ MAV Lead Engineer, ISPT, 21000 Brookpark Road/MS 77-4, AIAA Senior Member

5 Aerocapture Project Manager, 1 North Dryden Street,/MS 489, AIAA Senior Member

${ }^{6}$ MMEEV Project Manager, 1 North Dryden Street,MS 489
} 


\section{Nomenclature}

\begin{tabular}{|c|c|c|c|}
\hline$A M B R$ & $=$ Advanced Material Bi-propellant Rocket & $M M E E V$ & $=$ Multi-Mission Earth Entry Vehicle \\
\hline$A X F S$ & $=$ Advanced Xenon Feed System & $M S F C$ & $=$ Marshall Space Flight Center \\
\hline $\mathrm{COPV}$ & $=$ Composite Overwrap Pressure Vessel & MSR & $=$ Mars Sample Return \\
\hline$D C I U$ & Digital Control Interface Unit & MSL & $=$ Mars Science Laboratory \\
\hline$E D L$ & Entry, Descend, and Landing & $N A S A$ & $=$ National Aeronautics and Space \\
\hline EEV & Earth Entry Vehicle & & Administration \\
\hline$E M$ & Engineering Model & $N E X T$ & $=$ NASA Evolutionary Xenon Thruster \\
\hline$E M C$ & Electromagnetic Compatibility & NRA & $=$ NASA Research Announcement \\
\hline EMI & $=$ Electromagnetic Interference & NSTAR & $=$ NASA Solar Electric Propulsion Technology \\
\hline$E R V$ & $=$ Earth Return Vehicle & & Readiness \\
\hline$F C M$ & $=$ Flow Control Module & OTIS & $=$ Optimal Trajectories by Implicit Simulation \\
\hline GLOM & $=$ Gross Life-off Mass & $P A V$ & $=$ Planetary Ascent Vehicles \\
\hline$G N \& C$ & $=$ Guidance, Navigation and Control & $P C M$ & Pressure Control Module \\
\hline$G R C$ & Glenn Research Center & $P D R$ & $=$ Preliminary Design Review \\
\hline GSFC & Goddard Space Flight Center & $P M$ & $=$ Prototype Model \\
\hline HIVHAC & $=$ High Voltage Hall Accelerator & POST & $=$ Program to Optimize Simulated Trajectories \\
\hline$H P A$ & $=$ High Pressure Assemblies & $P P U$ & $=$ Power-Processing Unit \\
\hline$I P D T$ & $=$ Integrated Product Development Team & $S D T$ & $=$ Science Definition Team \\
\hline$I_{s p}$ & $=$ Specific impulse, second(s) & $S E P$ & $=$ Solar Electric Propulsion \\
\hline ISPT & $\begin{array}{l}=\text { In-Space Propulsion Technology Program or } \\
\text { office }\end{array}$ & $S M D$ & $\begin{aligned}= & \text { Science Mission Directorate at NASA } \\
& \text { Headquarters }\end{aligned}$ \\
\hline$J P L$ & $=$ Jet Propulsion Laboratory & $S O A$ & $=$ State of the Art \\
\hline$J S C$ & $=$ Johnson Space Center & $T P S$ & $=$ Thermal Protection Systems \\
\hline LaRC & $=$ Langley Research Center & $T R L$ & $=$ Technology Readiness Level \\
\hline$L P A$ & $=$ Low-Pressure Assemblies & TSTO & $=$ Two Stage to Orbit \\
\hline LTTT & $=$ Low-Thrust Trajectory Tool & $\Delta V$ & $=$ Velocity increment for propulsion system or \\
\hline MALTO & $=$ Mission Analysis Low Thrust Optimization & & spacecraft \\
\hline$M A V$ & $=$ Mars Ascent Vehicle & & \\
\hline
\end{tabular}

\section{Introduction}

NASA's Science Mission Directorate (SMD) missions seek to answer important science questions about our planet, the Solar System and beyond. To meet NASA's future science mission needs, the goal of the ISPT Program is the development of new enabling propulsion technologies that cannot be reasonably achieved within the cost or schedule constraints of mission development timelines. Since 2001, the In-Space Propulsion Technology (ISPT) Program has been developing inspace propulsion technologies that will enable and/or benefit near and mid-term NASA robotic science missions by significantly reducing cost, mass, and/or travel times. ISPT technologies will help deliver spacecraft to SMD's destinations of interest. In 2009, the ISPT program was tasked to start development of propulsion technologies that would enable future sample return missions.

An objective of ISPT is to develop capabilities that realize near-term and mid-term benefits. The Program primarily focuses on technologies in the mid TRL range (TRL 3 to $6+$ range) that have a reasonable chance of reaching maturity in 4-6 years. The objective is to achieve technology readiness level (TRL) 6 and reduce risk sufficiently for mission infusion. The project strongly emphasizes developing propulsion products for NASA flight missions, that will be ultimately manufactured by industry and made equally available to all potential users for missions and proposals.

The ISPT priorities and products are tied closely to the science roadmaps, the SMD's science plan, and the decadal surveys. ISPT therefore emphasizes technology development with mission pull. In 2006, the Solar System Exploration (SSE) Roadmap ${ }^{1}$ identified technology development needs for Solar System exploration, and described transportation technologies as highest priority, with the highest priority propulsion technologies being electric propulsion and aerocapture. Excerpts from the science community are discussed in Ref. 2. Initially, ISPT's responsibility was to develop technologies for Flagship missions, but in 2006 the focus evolved to technology investments that would be applicable to New Frontiers and Discovery competed missions. So, aerocapture (the use of aerodynamic drag for orbit capture) and electric propulsion continued to be a priority, but the refocus activity recommended a long-life lower-power Hall system.

Looking towards ISPT's future, the 2011 Planetary Science Decadal Survey ${ }^{3}$ was released March 2011, and will provide guidance for ISPT's future technology investments. The Decadal Survey made many references to ISPT technologies such as aerocapture, NEXT, AMBR, and astrodynamics, mission trajectory and planning tools. This Decadal Survey is validating the technology investments ISPT has been making over the last 10 years, and provides ISPT with a new focus for the next 10 to 20 years.

The Decadal Survey supported NASA developing a multi-mission technology investment program that will "preserve its 
focus on fundamental system capabilities rather than solely on individual technology tasks." The Decadal Survey highlighted the NEXT system development as an example of this "integrated approach" of "advancement of solar electric propulsion systems to enable wide variety of new missions throughout the solar system." The Decadal Survey also recommends "making similar equivalent systems investments" in the advanced Ultraflex solar array technology and aerocapture. The Decadal Survey discussed the importance of developing those system technologies to TRL 6.

One recommendation in the Decadal Survey was for "a balanced mix of Discovery, New Frontiers, and Flagship missions, enabling both a steady stream of new discoveries and the capability to address larger challenges like sample return missions and outer planet exploration." These broad mission needs would in turn require a balanced set of multi-mission technologies and integrated system capabilities. The Survey acknowledges that a "robust Discovery and New Frontiers Program would be substantially enhanced by such a commitment to multi-mission technologies."

This paper provides a brief overview of the In-Space Propulsion Technology (ISPT) program, describing the planning and development status of In-Space Propulsion technologies in the areas of electric propulsion for Earth Return Vehicles (ERV) and Discovery-class missions, planetary ascent vehicles, Earth return vehicles, other advanced propulsion technologies, and mission/systems analysis. These In-Space Propulsion technologies are applicable, and potentially enabling for future NASA flagship and sample return missions currently under consideration, as well as having broad applicability to future Discovery and New Frontiers mission solicitations. For more background on ISPT, please see Ref. 4, 5.

\section{Technology Development Overview}

ISPT emphasizes technology development with mission pull. In the near-term, the ISPT goal will be to develop propulsion technologies for sample return and Discovery-class missions. Sample return missions could be quite varied, from collecting and bringing back samples of comets or asteroids, to soil, rocks, or atmosphere from planets or moons. The current technology development areas for ISPT are: 1) Sample Return Propulsion (SRP), 2) Planetary Ascent Vehicles (PAV), 3) Entry Vehicle Technology (EVT) focus area, and 4) Systems/mission analysis and tools that focuses on sample return propulsion.

The focus of the Sample Return Propulsion (SRP) area is divided into: 1) Electric propulsion for sample return and low cost Discovery-class missions, 2) Propulsion systems for Earth Return Vehicles (ERV) including transfer stages to the destination, and 3) Propulsion system components and low TRL advanced propulsion technologies. The SRP effort will complete the development to TRL 6 of the NEXT ion engine system and will continue work on HIVHAC thruster development in FY2011. The HIVHAC thruster will then transition into a development of a HIVHAC system under future Electric Propulsion for sample return (ERV and transfer stages) and low-cost missions. Previous work on the lightweight propellant-tanks will continue under advanced propulsion technologies for sample return with direct applicability to a Mars Sample Return (MSR) mission and with general applicability to all future planetary spacecraft.

The current focus of the Planetary Ascent Vehicles (PAV) area is the technology development for a Mars Ascent Vehicle (MAV). The Planetary Ascent Vehicles (PAV)/Mars Ascent Vehicle (MAV) is a new development area to ISPT, but builds upon and leverages the past MAV analysis and technology developments from the Mars Technology Program (MTP) and previous MSR studies. The MAV is a key component of any future MSR mission. The Entry Vehicle Technology (EVT) area is divided into three main areas: 1) Aerocapture, 2) Multi-mission technologies for Earth Entry Vehicles (MMEEV), and 3) Planetary probes and impactors. ISPT's earlier Aerocapture efforts will be concluded in 2011, and ISPT is working to find opportunities to transition the technology into future flight opportunities. The Aerocapture experience base and capability will be leveraged with previous work related to Earth Entry Vehicles (EEV) and transitioned into the future multi-mission technologies for Earth Entry Vehicles (MMEEV).

The systems analysis technology area performed numerous mission and system studies to guide technology investments and quantify the return on investment. Recent focus of the systems analysis area is on developing reference missions and conducting mission sensitivities to assist technology gap identification or application.

\section{NASA's Evolutionary Xenon Thruster (NEXT)}

Solar Electric Propulsion (SEP) enables missions requiring large post launch $\Delta \mathrm{V}$. SEP has applications to rendezvous and sample-return missions to small bodies and fast trajectories towards the outer planets. Electric propulsion is both an enabling and enhancing technology for reaching a wide range of targets. The high specific impulse, or efficiency of electric propulsion system, allows direct trajectories to multiple targets that are chemically infeasible. The technology allows for rendezvous missions in place of fly-bys, and as planned in the Dawn mission, can enable multiple destinations.

This technology offers major performance gains, only moderate development risk, and has significant impact on the capabilities of new missions. Current plans include completion of the NASA's Evolutionary Xenon Thruster (NEXT) Ion Propulsion System target at Flagship, New Frontiers and demanding Discovery missions.

The GRC-led NEXT project was competitively selected to develop a nominal 40 -cm gridded-ion electric propulsion system. ${ }^{5}$ The objectives of this development were to improve upon the state-of-art (SOA) NASA Solar Electric Propulsion Technology Application Readiness (NSTAR) system flown on Deep Space-1 to enable flagship class missions by achieving the performance characteristics listed in Table 1. 
The ion propulsion system components developed under the NEXT task include the ion thruster, the power-processing unit (PPU), the feed system, and a gimbal mechanism. The NEXT project is developing prototype-model (PM) fidelity thrusters through Aerojet Corporation. In addition to the technical goals, the project has the goal of transitioning thruster-manufacturing capability with predictable yields to an industrial source. To prove out the performance and life of the NEXT thruster, a series of tests have, or are being, performed. The NEXT PM thruster completed a shortduration test in which overall ion-engine performance was steady with no indication of performance degradation. A NEXT PM thruster has also passed qualification level environmental testing (Fig. 1). As of June 30, 2011 the Long Duration Test (LDT) of the NEXT engineering model (EM) thruster achieved over 625.9-kg xenon throughput, $23.6 \times 10^{6} \mathrm{~N}$-s of total impulse, and 36,729 hours at multiple throttle conditions. The NEXT LDT wear test demonstrates the largest total impulse ever achieved by a griddedion thruster. ISPT funding for the thruster life test continues through FY12 with the aim of demonstrating up to $750 \mathrm{~kg}$ of xenon throughput. ${ }^{6}$

The NEXT thruster has clear mission advantages for very challenging missions. For example, the Dawn Discovery Mission only operates one NSTAR thruster at a time, but requires a second thruster for throughput capability. For the same mission, the NEXT thruster could deliver mass, equivalent to doubling the science package, with only a single thruster. Reducing the number of thrusters reduces propulsion system complexity and spacecraft integration challenges. The NEXT thruster can enable lower cost implementation by eliminating system complexity. Comparisons between the State-of-the-Art (SOA) NSTAR thruster and the NEXT thruster are shown below in Table 1.

The missions that are improved through the use of

Table 1. NEXT ion thrusters

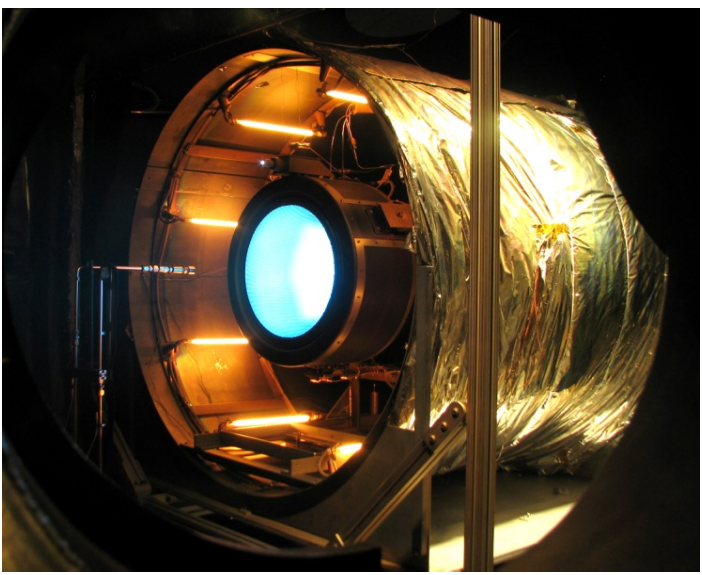

Figure 1. at JPL

\begin{tabular}{|lcc|}
\hline \multicolumn{1}{|c}{ Characteristic } & $\begin{array}{c}\text { NSTAR } \\
\text { (SOA) }\end{array}$ & NEXT \\
\hline Max. Thruster Power (kW) & 2.3 & 6.9 \\
\hline Max. Thrust (mN) & 91 & 236 \\
\hline $\begin{array}{l}\text { Throttle Range (Max./Min. } \\
\text { Thrust) }\end{array}$ & 4.9 & 13.8 \\
\hline Max. Specific Impulse (sec) & 3120 & 4190 \\
\hline Total Impulse (x10 ${ }^{6}$ N-sec) & $>5$ & $>18$ \\
\hline Propellant Throughput (kg) & 200 & 750 \\
\hline
\end{tabular}
the NEXT thruster are those requiring significant postlaunch $\Delta \mathrm{V}$, such as sample returns, highly inclined, or deep-space body rendezvous missions. The comet sample-return mission was studied for several destinations because of its high priority within the New Frontiers mission category. Electric propulsion enables a much wider range of feasible targets. Specifically for Temple 1 in Ref. 5 the NSTAR thruster is able to complete the mission, but requires large solar arrays and four or five thrusters to deliver the required payload. NEXT would be able to deliver ten percent more total mass and require half the number of thrusters.

Additional information on the NEXT system can be found in the NEXT Ion Propulsion System Information Summary in the New Frontiers and Discovery Program libraries. ${ }^{6,8}$

\section{Electric Propulsion for Sample Return and Discovery-class Missions}

ISPT is investing in Sample Return Propulsion technologies for applications such as Earth-Return Vehicles for large and small bodies. The first example leverages the development of a High-Voltage Hall Accelerator (HIVHAC) Hall thruster into a lower-cost electric propulsion system. ${ }^{4}$ HIVHAC is the first NASA electric propulsion thruster specifically designed as a low-cost electric propulsion option. It targets Discovery and New Frontiers missions and smaller mission classes. The HIVHAC thruster does not provide as high a maximum specific impulse as NEXT, but the higher thrust-to-power and lower power requirements are suited for the demands of some Discovery-class missions and sample return applications. Advancements in the HIVHAC thruster include a large throttle range from $0.3-3.5 \mathrm{~kW}$ allowing for a low power operation. It results in the potential for smaller solar arrays at cost savings, and a longlife capability to allow for greater total impulse with fewer thrusters. It

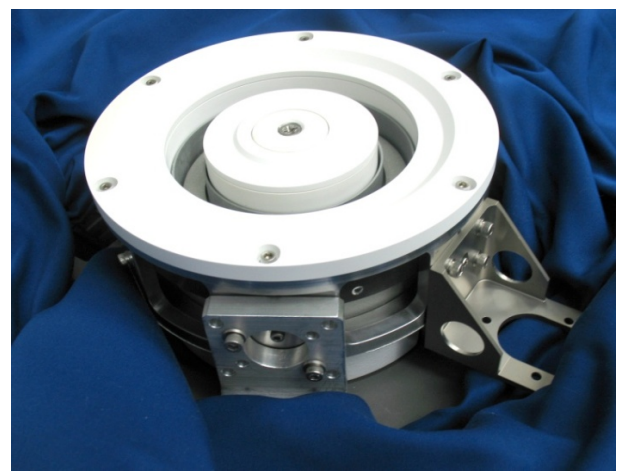

Figure 2. HIVHAC thruster Engineering Model 
allows for cost benefits with a reduced part count resulting in less complex and lower cost propulsion system.

Wear tests of the NASA-103M.XL thruster validated and demonstrated a means to mitigate discharge channel erosion as a life limiting mechanism in Hall thrusters. The thruster, shown in Fig. 2, operated in excess of 5500 hours (115 kg of xenon throughput) at a higher specific impulse (thruster operating voltage) as compared to SOA Hall thrusters.

Components for two Engineering Model (EM) thrusters were designed and fabricated. Preliminary performance mapping of the EM thruster at various operating conditions was performed at NASA Glenn Research Center (GRC). ${ }^{4}$ In the future, the test sequence will include performance acceptance tests, environmental tests and a long duration test in FY11 and FY12. Current plans include the design, fabrication and assembly of a full Hall propulsion system, but are pending final approval to proceed.

In addition to the thruster development, the HIVHAC project is evaluating power processing unit (PPU) and xenon feed system XFS development options that were sponsored by other projects but can apply directly to a HIVHAC system. The goal is to advance the TRL level of a Hall propulsion system to level 6 in preparation for a first flight.

The functional requirements of a HIVHAC PPU are operation over a power throttling range of 300 to $3,800 \mathrm{~W}$, over a range of output voltages between 200 and $700 \mathrm{~V}$, and output currents between 1.4 and $5 \mathrm{~A}$ as the input varies over a range of 80 to $160 \mathrm{~V}$. A performance map across these demanding conditions was generated for one candidate option ${ }^{4}$ that is being developed through NASA Small Business Innovation Research (SBIR) Program. Beyond conventional feed system options, one option for feed systems that was demonstrated with the Hall thruster is the advanced xenon feed system, developed by VACCO.

To continue to simplify and reduce the cost of the HIVHAC system, the ISPT project has invested in its reliable, lightweight, and low-cost xenon flow control system. ${ }^{9}$ A follow-on contract was awarded to VACCO as a joint ISPT and Air Force effort to qualify a Hall system module. This module would significantly reduce the cost, mass, and volume of a Hall thruster xenon control system while maintaining high reliability and decreasing tank residuals. This is the first time the ISPT project has advanced a component technology to TRL 8 to further reduce the risk and cost of the first user. The new Hall module is shown in Fig. 3. The Hall module is scheduled to complete its qualification program in August of 2011. The module is then planned for inclusion in a long duration test as an integrated string test of the HIVHAC system.

For the Near-Earth Object (NEO) mission evaluated, the HIVHAC thruster system delivered over 30 percent more mass

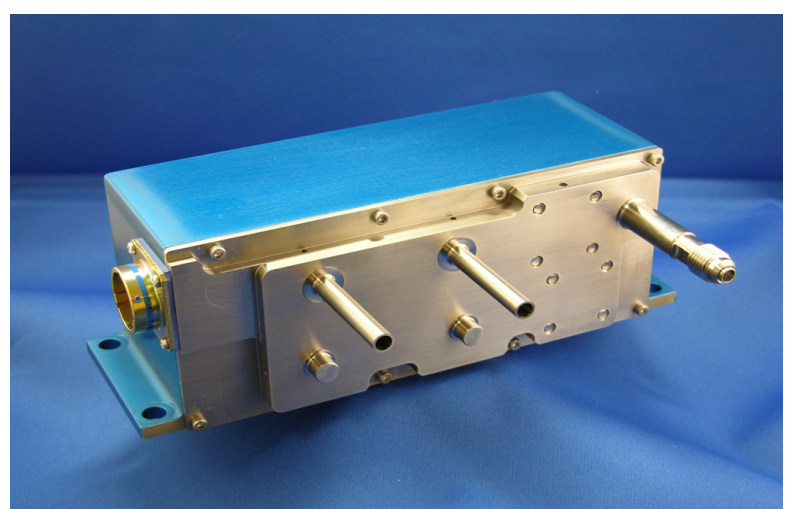

Figure 3. module.

than the NSTAR system. The performance increase accompanied a cost savings of approximately 25 percent over the SOA NSTAR system. The Dawn mission was evaluated, and the expected HIVHAC Hall thruster delivered approximately 14 percent more mass at substantially lower cost than SOA, or decreasing the solar array provided equivalent performance at even greater mission cost savings. ${ }^{4}$

The second technology example of a Sample Return Propulsion Technology is the BPT-4000 Hall thruster development. ISPT has invested in a life-test extension of the thruster to improve total impulse demonstrated capabilities. Under evaluation is the operation of this thruster design at higher operating voltages, which improve thruster specific impulse. There are mission studies that indicate that BPT-4000 is directly applicable to ERV and Discovery-class missions.

\section{Propulsion Component Technologies}

ISPT invests in the evolution of component technologies that offer significant performance improvements without increasing system level risk. Two component technologies currently receiving investments are xenon feed systems (discussed in the previous section) and Ultra-Light Tank Technology (ULTT).

The ISPT Program has been investing in ultra lightweight tank technology (ULTT) led by JPL. The ULTT efforts in the past have focused on manufacturability and non-destructive evaluation of the lightweight tanks. The tank effort continues to validate defectdetection techniques to maintain NASA standard compliance for ultra-thin wall tanks with follow-on potential to develop and qualify positive expulsive ultra light-weight tanks specifically for the MSL SkyCrane. The SkyCrane tanks could offer mass savings on the order of $24-30 \mathrm{~kg}$, dependent on the final tank wall thickness, which

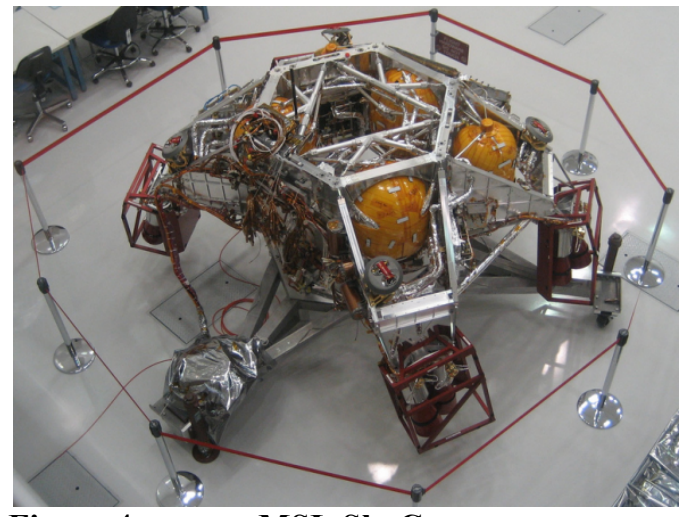

Figure 4.
MSL SkyCrane 
increase the landed mass capability of SkyCrane for a relatively low cost per kg. The SkyCrane EDL system is planned for the 2018 NASA/European Space Agency Mars mission and for the MSR lander. Both are highly mass constrained. The MSL SkyCrane, with large propellant tanks, is shown in Fig. 4. While the tanks will be qualified for the SkyCrane application, the technology will be broadly applicable for a wide range of future science missions. Propulsion tanks remain the highest drymass reduction potential within chemical propulsion systems, and this technology would significantly push the state-ofthe-art.

\section{Multi-Mission Earth Entry Vehicle (MMEEV)}

The Multi-Mission Earth Entry Vehicle (MMEEV) is a flexible design concept which can be optimized or tailored by any sample return mission, including lunar, asteroid, comet, and planetary (e.g. Mars), to meet that mission's specific requirements. Based on the Mars Sample Return (MSR) Earth Entry Vehicle (EEV) design, which due to planetary protection requirements is designed to be the most reliable space vehicle ever flown, the MMEEV concept provides a logical foundation by which any sample return mission can build upon in optimizing an EEV design which meets their specific needs. By leveraging common design elements, this approach can significantly reduce the risk and associated cost in development across all sample return missions. It provides significant feed-forward risk reduction in the form of technology development, testing, and even flight experience, for an eventual MSR implementation.

The current MMEEV parametric configuration is presented in Fig. 5 (basic vehicle architecture). Because each individual sample return mission may have a unique set of performance metrics of highest interest, the goal is to provide a qualitative performance comparison across a specified trade space. Each sample return mission can then select the most desirable design point from which to begin a more optimized design.

Continued development of the MMEEV models is planned to include: more sophisticated parametric configuration, including payload accommodation, models; higher fidelity impact dynamics model (e.g. finite-element model); updated aerodynamics models based on ground (e.g. wind tunnel and ballistic range) testing as well as Computational Fluid Dynamics (CFD) analysis; and high fidelity TPS mass/thickness sizing models for additional candidate TPS materials. MMEEV performance studies will continue with the eventual integration of the MMEEV models into an EDL "Quicklook" Tool, a prototype EDL analysis tool, originally developed in support of ISPT aerocapture studies. This tool is currently being developed to support mission studies to any celestial body with an atmosphere.

The biggest challenge for any space vehicle, including the MMEEV, is to adequately prove the reliability of the components, subsystems, and the flight system as a whole. The current

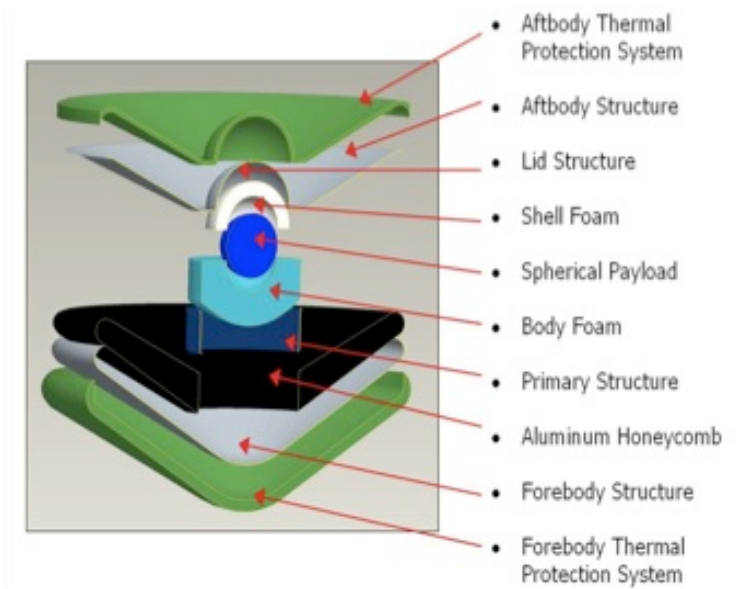

Figure 5. Basic MMEEV architecture estimate to develop the EEV technology for MSR to TRL 6 is approximately $\$ 41$ million. This does not include a dedicated flight test which, many experts agree, is needed to achieve the $10^{-6}$ probability of failure, because the entry flight environment cannot be replicated in ground-based facilities. One way to achieve a flight validation for little extra cost to NASA is to use the MMEEV design concept, or at least the major components of the design, in sample return missions likely to fly prior to MSR, such as New Frontiers or Discovery. NASA Headquarters managers and the In-Space Propulsion Technology (ISPT) team are pursuing this approach, but currently there are no manifested missions that are planning to use an MSR EEV design.

\section{Aerocapture}

Aerocapture is the process of entering the atmosphere of a target body to practically eliminate the chemical propulsion requirements of orbit capture. Aerocapture is the next step beyond aerobraking, which relies on multiple passes high in the atmosphere using the spacecraft's drag to reduce orbital energy. Aerobraking has been used at Mars on multiple orbiter missions. Aerocapture, illustrated in Fig. 6, maximizes the benefit from the atmosphere by capturing into orbit in a single pass. Aerocapture represents a major advance over aerobraking techniques by flying at a lower altitude where the atmosphere is more dense. Keys to successful aerocapture are accurate arrival state knowledge, validated atmospheric models, sufficient vehicle control authority (i.e. lift-to-drag ratio), and robust guidance during the maneuver. A lightweight thermal protection system and structure will maximize the aerocapture mass benefits. 
Executing the aerocapture maneuver itself is what enables the great mass savings over other orbital insertion methods. If the hardware subsystems are not mass efficient, or if performance is so poor that additional propellant is needed to adjust the final orbit, the benefits can be significantly reduced. ISPT efforts in aerocapture subsystem technologies are focused on improving the efficiency and number of suitable alternatives for aeroshell structures and ablative thermal protection systems (TPS). These include development of families of low and medium density (14-36 lbs/ft3) TPS and the related sensors, development of a carbon-carbon rib-stiffened rigid aeroshell, and high temperature honeycomb structures and adhesives. Development occurred on inflatable decelerators through concept definition and initial design and testing of several inflatable decelerator candidates. Finally, progress has been made through improvement of models for atmospheres, aerothermal effects, and algorithms and testing of a flight-like guidance, navigation and control (GN\&C) system.

Aerocapture has been proven repeatedly in detailed analyses to be an enabling or strongly enhancing technology for several atmospheric targets. The ISPT project team continues to mature aerocapture component in preparation for a flight demonstration, and rapid aerocapture analysis tools are being developed and made available to a wider user community. The TPS materials developed through ISPT enhance a wide range of missions by reducing the mass of entry vehicles. Some of the remaining gaps for technology infusion are efficient TPS for Venus and high-speed Earth return. All of the other component subsystems for an aerocapture vehicle are currently at or funded to reach TRL 6 in the next year. This assessment of technology readiness is detailed in Ref. 10. The structures and TPS subsystems as well as the aerodynamic and aerothermodynamic tools and methods can be applied to small-scale entry missions even if the aerocapture maneuver is not utilized.

The Aerocapture system cannot reach TRL 6 without space flight validation, because it is impossible to match the flight environment in ground facilities. This validation can be accomplished by utilizing Aerocapture on a science mission, or by a dedicated space flight validation experiment. NASA's Science Mission Directorate has incentivized the use of Aerocapture in its recent Discovery Announcement of Opportunity. Since a Discovery mission utilizing Aerocapture was not selected, Aerocapture will likely seek other opportunities to be validated in space. A space flight validation is expensive, but the costs will be recouped very quickly if just one mission's launch vehicle cost is reduced as a result of the lower mass requirement enabled by Aerocapture. The validation immediately reduces the risk to the first user and matures the maneuver for application to multiple, potentially lower-cost, missions to Titan, Mars, Venus, and Earth. Moreover, once Aerocapture is proven a reliable tool, it is anticipated that entirely new missions will become possible. Additional information on Aerocapture technology developments can be found in the Discovery Program library. ${ }^{7}$ Using Aerocapture produces significant cost benefits for multiple missions. When the overall system mass is reduced, the mission can utilize a smaller launch vehicle, saving tens of millions of dollars. Detailed mission assessment results can be found in the Aerocapturerelated references in Ref. 5.

\section{Planetary Ascent Vehicle (PAV)}

For many years, NASA and the science community asked for a Mars Sample Return (MSR) mission. There were numerous studies to evaluate MSR mission architectures, technology needs and development plans, and top-level requirements. Because of the challenges, technologically and financially of the MSR mission, NASA initiated a study to look at MSR propulsion technologies through the In-Space Propulsion Technology (ISPT) Program Office. The objective of the ISPT Program is to develop propulsion technologies that enhance or enable NASA science missions for the Planetary Science Division by increasing performance while reducing cost, risk, and/or trip length. The largest propulsion risk element of the MSR mission is the Mars Ascent Vehicle (MAV).

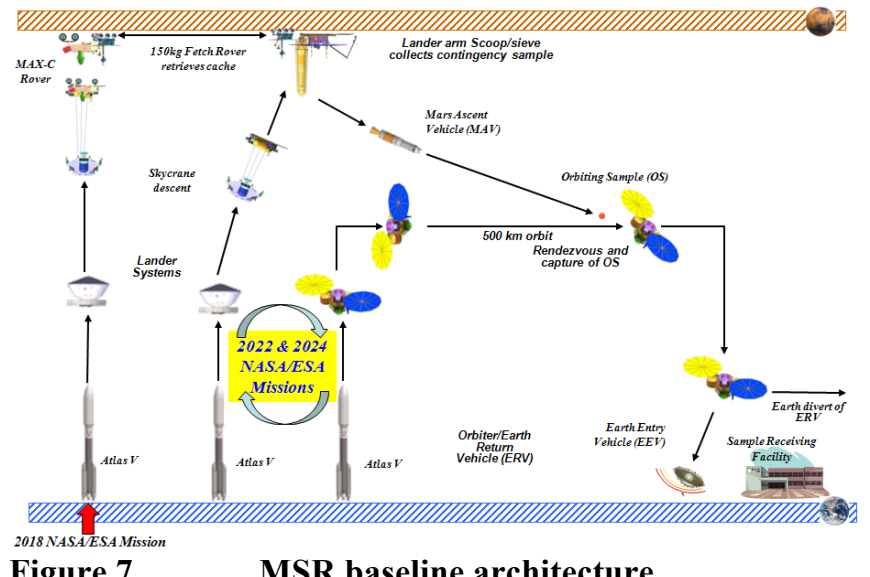

Figure 7. MSR baseline architecture 


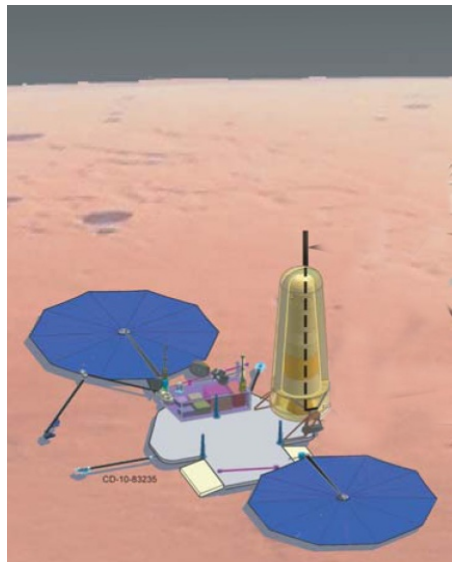

Figure 8. MAV

Launch Platform

The current architecture (Fig. 7) for the MSR lander is to use the Mars Science Laboratory (MSL) entry, descent, and landing (EDL) system. ${ }^{11}$ Using the MSL sky crane concept places significant environmental, physical envelope and mass limitations on the MAV system options.

Beyond the limitations of the EDL system, the MAV (Fig. 8) has specific requirements to deliver the orbiting sample (OS) into an orbit suitable for the Earth Return Vehicle (ERV). The basic requirements include:

- $\quad 500 \mathrm{~km}+/-100 \mathrm{~km}$ circular orbit

- $45^{\circ}+/-0.2^{\circ}$ inclination

- $\quad$ Ability to launch from $+/-30^{\circ}$ latitudes

- Accommodate $\sim 5 \mathrm{~kg}, 16 \mathrm{~cm}$ diameter payload

- Continuous telemetry

- $\quad$ Storage for 90 Sols, potentially up to one Martian year

Through the NASA Research Announcement (NRA) process, the ISPT project solicited MAV system designs and plans to initiate propulsion system development. Multiple contractors were selected to proceed in October of 2010 and efforts were initiated in February 2011. Awards were made to ATK, Lockheed Martin, and Northrop Grumman to develop MAV concepts using solidsolid, solid-liquid, and liquid-liquid $1^{\text {st }}$ and $2^{\text {nd }}$ stage propulsion systems respectively. During the NRA efforts, the contractors are completing Principal Investigator (PI) led collaborative engineering designs of the MAV with contract options to begin the required technology development. The base period rewards will be completed in early August with a goal to exercise technology development options early in FY12. The baseline MAV concept design is shown in Fig. 9. The baseline design is predecisional and for understanding design trades and sensitivities; it does not represent any concept selection.

\section{Systems/Mission Analysis}

Systems analysis is used during all phases of any propulsion hardware development. The systems analysis area serves two primary functions:

1) to help define the requirements for new technology development and the figures of merit to prioritize the return on investment,

2) to develop new tools to easily and accurately determine the mission benefits of new propulsion technologies allowing a more rapid infusion of the propulsion products.

Systems analysis is critical prior to investing in technology development. In today's environment, advanced technology must maintain its relevance through mission pull. Recent systems analysis efforts have included quantitative assessment of higher specific impulse Hall thrusters, ${ }^{12}$ higher thrust-to-power gridded-ion engines, and evaluation of monoprop system anomalies to assess failure modes and potential mitigation options.

The second focus of the systems analysis project area is the development and maintenance of tools for the mission and systems analyses. Improved and updated tools are critical to clearly understand and quantify mission and system level impacts of advanced propulsion technologies. A common set of tools increases confidence in the benefit of ISPT products both for mission planners as well as for potential proposal reviewers. For example, low-thrust trajectory analyses are critical to the infusion of new electric propulsion technology. The ability to calculate the performance benefit of complex electric propulsion missions are intrinsic to the determination of propulsion system requirements. The ability for the user community to rapidly and accurately access the mission level impacts of ISPT products can ease technology infusion. Every effort will be made to have these tools validated, verified, and made publicly available. Instructions to obtain the tools currently available are provided on the ISPT project web site. ${ }^{13}$ http://spaceflightsystems.grc.nasa.gov/Advanced/ScienceProject/ISPT/

The ISPT office invested in multiple low-thrust trajectory tools that independently verify low thrust trajectories at various degrees of fidelity. The ISPT low-thrust trajectory tools suite includes Mystic ${ }^{14}$, the Mission Analysis Low Thrust Optimization (MALTO) ${ }^{15}$ program, Copernicus ${ }^{16}$, and Simulated N-body Analysis Program (SNAP). SNAP is a high fidelity propagator. MALTO is a medium fidelity tool for trajectory analysis and mission design. Copernicus is suitable for both low and high fidelity analyses as a generalized spacecraft trajectory design and optimization program. Mystic is a high fidelity tool capable of N-body analysis and is the primary tool used for trajectory design, analysis, and operations of the Dawn mission. While some of the tools are export controlled, the ISPT web site does offer publicly available tools and includes instructions to request tools with limited distribution. The ISPT project team is planning a series of courses for training on the 
ISPT project tools. On-going tool advancements include providing MALTO and Mystic all platforms, bug fixes, and increased capabilities.

ISPT project released its Aerocapture Quicklook Tool, formally the multidisciplinary tool for Systems Analysis of Planetary EDL (SAPE). SAPE is a Python based multidisciplinary analysis tool for entry, decent, and landing (EDL) at Venus, Earth, Mars, Jupiter, Saturn, Uranus, Neptune, and Titan. The purpose of the SAPE is to provide a method of rapid assessment of aerocapture or EDL system performance, characteristics, and requirements. SAPE includes integrated analysis modules for geometry, trajectory, aerodynamics, aerothermal, thermal protection system, and structural sizing. For Aerocapture and EDL system designs, systems analysis teams typically include systems engineers and disciplinary specific experts in flight mechanics, aerodynamics, aerothermodynamics, structural analysis, and thermal protection systems (TPS). The systems analysis process may take from several weeks to years to complete. While the role of discipline experts cannot be replaced by any tool, the integrated capabilities of SAPE can automate and streamline several parts of the analysis process significantly reducing the time and cost, or preliminary assessment. SAPE continues to receive investment for assessment of Earth Entry Vehicles.

\section{Technology Infusion}

NASA recognizes that it is desirable to fly new technologies that enable new scientific investigations or to enhance an investigation's science return. The Solar System Exploration (SSE) Roadmap states that NASA will strive to maximize the payoff from its technology investments, either by enabling individual missions or by enhancing classes of missions with creative solutions. Discovery, New Frontiers, and Flagship missions potentially provide opportunities to infuse advanced technologies developed by NASA, and advance NASA's technology base and enable a broader set of future missions.

To benefit from its technology investments, NASA provided incentives for infusion of new technological capabilities that it had developed in the most recent New Frontiers and Discovery competed mission solicitations. The incentives for NEXT, AMBR, Aerocapture, and the Advanced Stirling Radioisotope Power System (ASRG) were in the form of increases to the cost cap for the mission, or providing the ASRG as Government Furnished Equipment (GFE). AMBR stands for the Advanced Materials Bi-propellant Rocket engine, which ISPT and Aerojet completed the development to TRL 6 in 2009. The Decadal Survey states "these technologies continue to be of high value to a wide variety of solar system missions." And that "NASA should continue to provide incentives for these technologies until they are demonstrated in flight." The 2011 Planetary Decadal Survey strongly supported continuing to incentivize these technologies until they are flown. ${ }^{3}$ As funding and priorities allow, ISPT will strive to maintain the capabilities associated with NEXT, AMBR, and aerocapture.

Beyond the New Frontiers and Discovery opportunities, ISPT continues to seek opportunities to infuse NEXT, AMBR, Aerocapture, and its other technologies into a wide range of possible future mission opportunities. The ISPT project office and NEXT team personnel are actively supporting various flagship science definition team (SDT) studies. See the ISPT Overview paper in the 2010 IEEE Aerospace Conference for more details regarding these studies. ${ }^{5,8}$ ISPT will continue to help in identifying the technology development that is required to accomplish the future missions being contemplated.

\section{Future Plans and Conclusion}

The future focus areas for ISPT are propulsion systems for sample return missions. Activity in these technology development areas continues in 2011 and increases in 2012 and 2013. The direction focuses on: 1) Planetary Ascent Vehicles; 2) multi-mission technologies for Earth Entry Vehicles required for sample return missions; and 3) electric and chemical propulsion for Earth Return Vehicles, transfer stages, and low cost Discovery-class missions. These sample return missions are inherently propulsion intensive. Several of the earlier ISPT technology areas may also be involved in a single sample return mission. The mission may use Electric Propulsion for transfer to, and possibly back from, the destination. Chemical propulsion may be utilized for the ascent and descent to the surface. Aeroshells may be used for Earth re-entry and an aerocapture maneuver used to capture at the destination. Future sample return missions of interest for NASA and the science community, and those that are yet to be conceived, continue to demand propulsion systems with increasing performance and lower cost. This paper addressed how the ISPT project is starting to develop propulsion technologies for NASA's future sample-return missions.

\section{Acknowledgments}

The results and findings presented here are based on work funded by the National Aeronautics and Space Administration (NASA), Science Mission Directorate (SMD). ISPT implements the project through task agreements with NASA centers, contracts with industry, and via grants with academic institutions. Implementing NASA centers include Ames Research Center (ARC), Glenn Research Center (GRC), Jet Propulsion Laboratory (JPL), Langley Research Center (LaRC), and the Marshall Space Flight Center (MSFC). There are also numerous industry partners in the development of the ISPT products. The authors acknowledge the technical achievements by the respective NASA and contractor teams and the contributions of the respective technology area project managers. In addition, many thanks to Linda Nero for her administrative, editorial, and clerical support of this paper. 


\section{References}

1 “2006 Solar System Exploration Roadmap for NASA’s Science Mission Directorate,” September 2006.

2 Anderson, D. J. et al., "The NASA In-Space Propulsion Technology Project, Products, and Mission Applicability," 2009 IEEE Aerospace conference, March 2009, Paper \#1176.

3 "Vision and Voyages for Planetary Science in the Decade 2013-2022," The National Academies Press, URL: http://www.nap/edu, 2011

${ }^{4}$ Anderson, D. J. et al., "In-Space Propulsion Technology Products for NASA's Future Science and Exploration Missions,” 2011 IEEE Aerospace conference, March 2011, Paper \#1114.

5 Anderson, D. J. et al., "Sample Return Propulsion Technology Development under NASA's ISPT Project," 2011 IEEE Aerospace conference, March 2011, Paper \#1115

6 “NASA's Evolutionary Xenon Thruster (NEXT) Ion Propulsion system Information Summary Aug. 2008," New Frontiers Program Library Web site URL: http://newfrontiers.larc.nasa.gov/NFPL.html

${ }^{7}$ Discovery Program Library Web site URL: http://discovery.larc.nasa.gov/dpl.html

${ }^{8}$ New Frontiers Program Library Web site URL: http://newfrontiers.larc.nasa.gov/NFPL.html

${ }^{9}$ Dankanich, J. Cardin, J., Dien, A., Netwall, C., Osborn, M., and Kamhawi, H., “Advanced Xenon Feed System (AXFS) Development and Hot-fire Testing," AIAA-2009-4910, 45 ${ }^{\text {th }}$ Joint Propulsion Conference, Denver, CO, August 2-6, 2009.

${ }^{10}$ Anderson, D. J. et al., "The NASA In-Space Propulsion Technology Project's Current Products, and Future Directions," 2010 IEEE Aerospace conference, March 2010, Paper \#1078

${ }^{11}$ Mattingly, R., and May, L., "Mars Sample Return as a Campaign," IEEEAC Paper \#1805, 2011 IEEE Aerospace Conference, Big Sky, MT, March 5-12, 2011.

${ }^{12}$ Dankanich, J. W., Kamhawi, H., and Mathers, A., "HiVHAC Maximum Operating Power Mission Impacts," IEPC-2009-213, 2009 International Electric Propulsion Conference, Ann Arbor, MI, September 20-24, 2009.

${ }^{13}$ NASA ISPT Web site URL: http://spaceflightsystems.grc.nasa.gov/Advanced/ScienceProject/ISPT/LTTT/.

${ }^{14}$ Whiffen, G., "Mystic: Implementation of the Static Dynamic Optimal Control Algorithm for High-Fidelity Low-Thrust Trajectory Design," AIAA-2006-6741, AIAA/AAS Astrodynamics Specialist Conference, Keystone, CO, August 21-24, 2006.

${ }^{15}$ Sims, J., Finlayson, P., Rinderle, E., Vavrina, M., and Kowalkowski, T., “AIAA-2006-6746, AIAA/AAS Astrodynamics Specialist Conference, Keystone, CO, August 21-24, 2006.

${ }^{16}$ Ocampo, C., Senent, J. S., and Williams, J., "Theoretical Foundation of Copernicus: A Unified System for Trajectory Design and Optimization,” NASA Technical Reports Server, Document ID: 20100017708; Report Number: JSC-CN-20552, May, $21,2010$. 